Results: There was a total of 262 survey participants (130 KD and 132 ageand sex matched healthy controls). There was no significant difference in the frequency of clinically significant sleep disturbance between patients with KD and healthy controls. However, the total sleep score was significantly higher in KD patients than health controls $(p<.001)$. Total sleep duration was significantly higher in patients with KD $(4.94 \pm 1.88$ vs $3.74 \pm 1.14 \mathrm{hr}, \mathrm{p}<.001)$. Additionally KD patients had significantly higher scores regarding sleep onset delay $(p=.001)$, night wakings $(p<.001)$, parasomnias $(p<.001)$ and sleep disordered breathing $(p<.001)$ when compared to healthy controls.KD Patients who manifested with chronic heart disease or lethargy had significantly higher sleep score than patients without ( $p=.015, .039$ respectively).

Conclusion: This study showed that patients with KD had more sleep disturbance than their healthy peers. The presence of either chronic heart disease or lethargy is associated with poor sleep quality.This study highlights the need for assessment of sleep disorders in KD patients.

REFERENCES:

[1] Hedrich CM, Schnabel A, Hospach T. Kawasaki Disease. Front Pediatr. 2018;6:198-.

[2] Singh S, Gupta MK, Bansal A, Kumar RM, Mittal BR. A comparison of the clinical profile of Kawasaki disease in children from Northern India above and below 5 years of age. Clinical and experimental rheumatology. 2007;25(4):654-7.

[3] van Golde EG, Gutter T, de Weerd AW. Sleep disturbances in people with epilepsy; prevalence, impact and treatment. Sleep medicine reviews. 2011;15(6):357-68

[4] Roehrs T, Diederichs C, Gillis M, Burger AJ, Stout RA, Lumley MA, et al. Nocturnal sleep, daytime sleepiness and fatigue in fibromyalgia patients compared to rheumatoid arthritis patients and healthy controls: a preliminary study. Sleep medicine. 2013;14(1):109-15.

[5] Silva FG, Silva CR, Braga LB, Serrão Neto A. Portuguese Children's Sleep Habits Questionnaire-validation and cross-cultural comparison. Jornal de pediatria. 2014;90(1):78-84.

Disclosure of Interests: None declared

DOI: 10.1136/annrheumdis-2021-eular.4081

\section{AB0754 THE INFLUENCE OF PHYSICAL ACTIVITY ON BODY COMPOSITION AND SELF-ESTEEM IN ADULTS WITH JUVENIL IDIOPATHIC ARTHRITIS}

R. De Oliveira ${ }^{1}$, P. Julio ${ }^{1}$, P. Fernandes ${ }^{2}$, R. Marini ${ }^{3}$, S. Appenzeller ${ }^{4}{ }^{1}$ UNICAMP, Child and Adolescent Graduate Program, Campinas, Brazil; ${ }^{2}$ UNICAMP, Sport Sciences, Campinas, Brazil; ${ }^{3}$ UNICAMP, Pediatrics, Campinas, Brazil; ${ }^{4}$ UNICAMP, Orthopedics, Rheumatology and Traumatology, Campinas, Brazil

Background: With improvement of treatment, long-term factors influencing quality of life have to be addressed in the care of juvenile idiopathic arthritis (JIA) patients.

Objectives: To compare body composition, level of physical activity and self-esteem of adult patients with JIA with control group (CG).

Methods: The levels of physical activity were analyzed using the International Physical Activity Questionnaire (IPAQ) short version. The body composition data were collected using the Omrom HBF $514 \mathrm{C}$ vertical electric bioimpedance device. The Rosenberg Self-Esteem Scale was used to assess positive and negative attitude and feelings about themselves, where the lower the score, the higher the individual's self-esteem. For the statistical analysis of the data, the IBM SPSS software was used with a significance index of $p<0.05$.

Results: We included 81 individuals $>18$ years, 38 with JIA and 43 healthy people. The female sex was the largest participant in this research, being. There was no significant difference regarding sex [female $=28(73.7 \%)$ in $\mathrm{JIA}$ and 26 $(60.5 \%)$ in CG] and age of the groups $(29.39 \pm 7.6$ vs. $31.1 \pm 3.1, p=0.18)$. The CG showed greater height and body weight $(163.5 \pm 9.8$ vs. $169.6 \pm 8.0$, $p<0.001 ; 63.07 \pm 16.65$ vs. $69.33 \pm 6.88, p=0.003$, respectively), but no difference in Body Mass Index (BMI) was observed (24.32 \pm 4.9 vs. $24.12 \pm 2.09$, p $=0.8)$. JIA had a higher percentage of total fat mass (31.65 \pm 10.20 vs. 28.47 $\pm 4.9, p=0.07)$, while the $C G$ had a higher percentage of total muscle mass $(29.7 \pm 6.5$ vs. $35.86 \pm 6.05, p<0.001)$. The self-esteem of JIA patients was lower than in the CG $(21 \pm 3.9$ vs. $16.26 \pm 4.3, p<0.001)$. In the IPAQ classifications, JIA patients were classified as less physically active than the CG $(2.63 \%$ vs. $20.93 \%, p=0.022)$, less irregularly active $(5.26 \%$ vs. $23.25, p=0.023)$ and a higher level of sedentary lifestyle $(65.78 \%$ vs. $25.58 \%, p<0.001)$. A higher percentage of muscle mass was associated with greater self-esteem $(r=-0.3$; $\mathrm{p}=0.01$ ).

Conclusion: The low practice of physical activities by patients with JIA seems to directly influence both, their body composition and their self-esteem. These patients should be encouraged to increase physical activity from an early age by a multiprofessional healthcare team to seek improvement their quality of life. Disclosure of Interests: None declared

DOI: 10.1136/annrheumdis-2021-eular.4085

\begin{tabular}{|l|l}
\hline AB0755 & THE FIRST CASE OF AN AUTOLOGOUS STEM \\
CELL TRANSPLANTATION FOR AN EXTREMELY \\
REFRACTORY PROGRESSIVE SYSTEMIC JUVENILE \\
IDIOPATHIC ARTHRITIS PATIENT IN BRASILIA, BRAZIL
\end{tabular}

M. Rodrigues Pereira Almeida ${ }^{1}$, S. Veloso ${ }^{1}$, A. Siqueira Afonso ${ }^{1} .{ }^{1}$ Hospital da Criança de Brasilia José Alencar, Pediatric Rheumatology, Brasilia, Brazil

Background: Systemic juvenile idiopathic arthritis (SJIA) is one of the most perplexing diseases of childhood, with a wide range of presentation features and severity. Advances in treatment have improved the outcome, such as the use of modulators of proinflammatory cytokines and their receptors, but in a consider able number of children, especially in polyarticular or SJIA, refractoriness tends to be progressive. As of late, extreme cases have required Autologous Stem Cell Transplantation (ASCT) as a last resort.

Objectives: To describe an extremely refractory clinical evolution in a sAlJ patient, the first one to be submitted to an ASCT for an autoinflammatory condition in Brasília, Brazil's capital.

Methods: Case Report

The patient was classified according to the Pediatric International League of Associations for Rheumatology for SJIA.

I.T.S.M, female, 15-years-old, was diagnosed with SJIA at 6 with the onset of polyarthritis, daily fever for 6 weeks, rash and enlargement of liver and spleen. In the initial investigation infectious and neoplastic causes were ruled out.

The use of prednisone and methotrexate lead to a preliminary effective clinical control, however after an year, there was clinical deterioration and etanercept was associated, leading to a short term improvement. At that time, in addition to anti-tumour necrosis factor medications, no other biological drugs were available in Brazil.

Despite some brief periods of clinical improvement, after different regimes, the patient manifested recurrent flares. Since the diagnosis she has already been treated with:

[1] Methotrexate (2011 to $2014^{*}, 2016$ to 2020 ). ${ }^{*}$ In 2015 , it was replaced by Leflunomide (up to May 2016, discontinued due to intolerance);

[2] Etanercept (2012);

[3] Cyclosporine (August to December 2012);

[4] Adalimumab (2013);

[5] Tocilizumab (May 2014 to January 2015);

[6] Canaquinumab (March 2015 to April 2016);

[7] Mycophenolate Mofetil (February 2016, discontinued in May 2017 due to start of Cyclophosphamide);

[8] Rituximab (May 2016 to April 2017);

[9] Cyclophosphamide at a dose of 2 grams $/ \mathrm{m} 2$ as well as Filgrastim for mobilization and collection of stem cells (May 2017, in a attempt of ASCT), but the parents were unable to reach a mutual agreement to consent to the continuation of this therapy;

[10] Cyclophosphamide $\left(500 \mathrm{mg} / \mathrm{m}^{2}\right)$ in a mensal scheme application for nine consecutive months since June 2017 , once was observed a clinical improvement after the intensive immunosuppression previous to ASCT attempt;

[11] Several courses of methylprednisolone and human immunoglobulin since the initial diagnosis;

[12] Abatacept (November 2019 to October 2020);

[13] ASCT was suggested again in 2020 , this time with the consent of all family members.

Results: An intensive immunosuppression [Cyclophosphamide and anti-thymocyte globulin (ATG)] followed by ASCT (October 2020) resulted in apparent sustained remission. The patient's evolution since the transplant has been optimistic. She is currently on a low dose prednisone prescription. To ensure a less profound depletion of $T$ cells, a better control of systemic disease and antimicrobial and antiviral prophylaxis after transplantation, slow tapering of corticosteroids were performed. Conclusion: The goal of hematopoietic stem cell transplantation in patients with autoimmune disease is to reprogram the immune system with the eradication of autoreactive cells, renew the population of regulatory $T$ cells and restore the diversity of $\mathrm{T}$ cell receptor function.

ASCT has been used in some refractory children with SJIA as well as hematologic malignancy and some progressive autoimmune diseases. However it is associated with significant morbidity and mortality, due to prolonged and severe depression of $T$ cell immunity.

REFERENCES:

[1] D.M.C. Brinkman et al. Arthritis Care \& Research (2007)

[2] Voltarelli Júlio C. et al. Rev. Bras. Hematol. Hemoter. (2010)

[3] Angelo De Cata et al. Clin Exp Med. (2016)

[4] Joost F. Swart et al. Nature Reviews Rheumatology (2017)

Acknowledgements: We kindly thank the Hematology service of Hospital da Criança de Brasília, where the patient was subjected to the autologous stem-cell transplantation.

Disclosure of Interests: None declared

DOI: 10.1136/annrheumdis-2021-eular.4132 